\title{
Streamlining a Transport Network Using GIS Technology
}

\author{
Ancuţa ROTARU ${ }^{1}$, Ioana POP ${ }^{2}$, Sorin VÂTC $\breve{A}^{3}$, Luisa ANDRONIE ${ }^{1}$, Mirela CADAR ${ }^{1}$, Anamaria VÂTC $\breve{A}^{1 *}$ \\ ${ }^{1}$ Faculty of Animal Science and Biotechnologies, University of Agricultural Sciences and Veterinary \\ Medicine, 3-5 Mănăştur Street, 400372 Cluj-Napoca, Romania \\ ${ }^{2}$ Faculty of Horticulture, University of Agricultural Sciences and Veterinary Medicine, 3-5 Mănăştur \\ Street, 400372 Cluj-Napoca, Romania \\ ${ }^{3}$ Faculty of Agriculture, University of Agricultural Sciences and Veterinary Medicine, 3-5 Mănăştur \\ Street, 400372 Cluj-Napoca, Romania \\ *corresponding author, e-mail: anamaria.vatca@usamvcluj.ro
}

Bulletin UASVM Animal Science and Biotechnologies 75(1)/ 2018

Print ISSN 1843-5262; Electronic ISSN 1843-536X

DOI:10.15835/buasvmcn-asb: 002717

\begin{abstract}
In today's environment, the success of an organization depends on the ability to reduce the decision cycle, make better decisions, and share strategic information within the organization. The model of this paper shows that the results of GIS processing are much more efficient in the information process - decision making, production, evidence, both in the transport sector and in other fields of activity.

The main purpose of a GIS system is, beside the introduction, storage and editing of some geographic, demographic, environmental information etc. The analysis and the study of this information in a relational context, in order to obtain complex decisions. Network analysis in GIS is most frequently related to finding new solutions to transport issues.
\end{abstract}

Keywords: networks analysis, transport streamlining, ArcGIS Network Analyst

\section{INTRODUCTION}

GIS represents the informatic system which couple a database which operate with geometric objects (spatial) with a database which operate with attributes of the information contained in the first database (Dimitriu, 2007). The results of GIS processing are not only incomparably more effective in the information process - decisionmaking, production, evidence - in which they have their place, but they make faster and better understanding of the facts and phenomena that are being analyzed or on which they act. One of the main applications of network analysis is found in transport planning, where the main issue is to identify optimal routes that meet certain criteria, such as finding the shortest route or the lowest cost between two or more locations, identifying all locations which falls into a certain cost (temporal or financial) (Băduț, 2007).

\section{AIMS AND OBJECTIVES}

The purpose of this paper is to create a transport network model containing warehouses and stores, and to optimize the time needed for the distances between them.

\section{MATERIALS AND METHODS}

In order to achieve this logistic model in Cluj County, 5 warehouses and 16 stores were considered, and we found out how many stores and how far these stores were located away from the warehouses within the coverage area thereof. The database that enabled this work was obtained from the national project "Digital Romania". Using the ArcGIS Network Analyst extension, it was possible to identify the area of influence of an economic objective on any location on the map representing the network. 


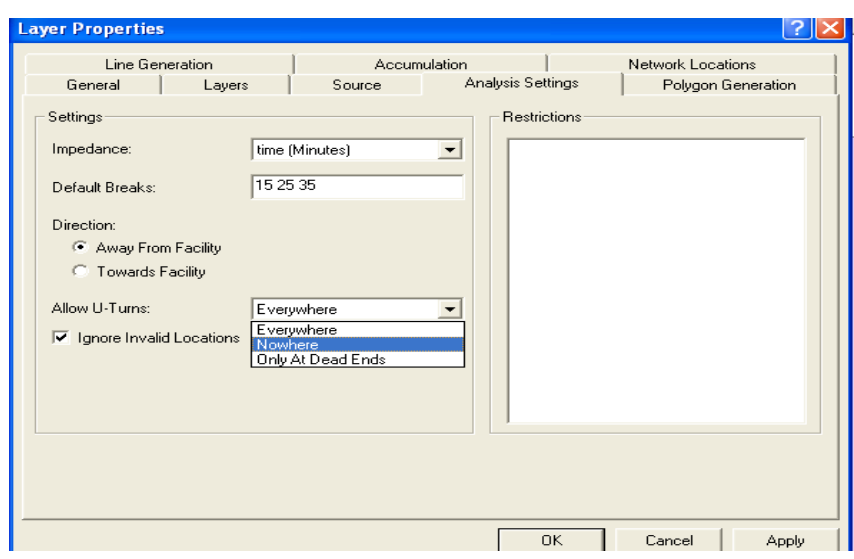

Figure 1. Network restrictions

\section{RESULTS AND DISCUSSION}

GIS is an indispensable tool in solving transport problems, having the ability to correlate and coordinate traffic in time and space. It can be used for the systematization and coordination of transport (road planning, public transport management, direct calculation of optimal routes for various types of intra-city journeys including restrictions).

In the first phase of the model using the ArcMap command was represented the first thematic layer, the Cluj County as surface and contour, then the layer for localities and roads. The map document contains several cartographic compositions called data frames. Thematic layers within a data frame should refer to the same territory, in this case the surface of Cluj County.

One of the most important features to be included in any surface topology model is impedance or network strength. This can be expressed by many quantitative features and most often shown in the attribute table. The most wellknown are the length of the network segment and the amount of time it takes to cross it. In the present model the impedance is expressed by the time interval, which is specified in the creation of the data structure. This was done in ArcCatalog by specifying that each element of the network becomes a distinct entity bounded by nodes of origin and destination, and between the segments there are special elements called junctions.

After the 5 warehouses and 16 stores are added to the map, the coverage area will be specified based on driving time. Three coverage area polygons will be calculated for each deposit, one for 15 , one for 25 and the other for 35 minutes.

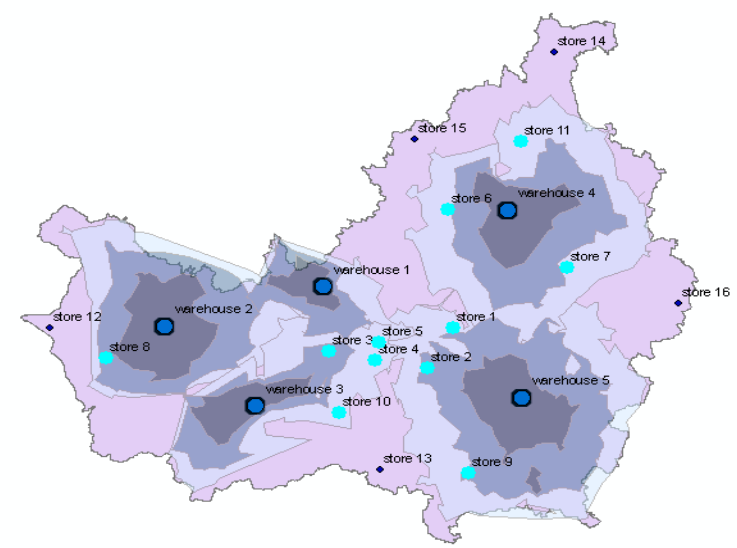

Figure 2. Assignment of stores to each deposit

It has been specified that the direction of travel will be from the warehouse, not to the warehouse, that no U-turns can be made and that one-way restrictions are respected. (Figure 1).

Figure 2 shows the map with the three areas of coverage where the three color shades can be seen, each shade being the corresponding impedance (ie, 15, 25 and 35 minutes). Also, stores that are not covered by any polygon (such as stores numbered $12,13,14,15,16)$ are displayed, the other being colored.

You can also display an attribute table that shows the total driving time from each warehouse to the 35-minute stores, for example from warehouse 4 , deliveries can be made during this time to three stores: to store 7 (in 24.2 minutes), to store 6 (in 26.6 minutes) and to store 11 (in 29.6 minutes).

\section{CONCLUSIONS}

Achieving a model using state-of-theart computer systems is essential to ensure accessibility and mobility opportunities in order to meet the current and forward-looking mobility needs, while respecting the requirements for the use of agricultural areas, road networks and observing the environmental conditions. The built-in model can generate far more complex approaches when introducing restrictions of various types: circulation can only take place on certain road categories (national and county roads), at certain time intervals and with certain speeds, or various restrictions imposed on the machinery. 


\section{REFERENCES}

1. Băduţ M (2007). GIS Sisteme informatice geografice, fundamente practice. Editura Albastră, Cluj-Napoca.

2. Bernhardsen T (1992). Geographic information system. Viak IT, Arendal, Norway.
3. Chou YH (1997). Exploring spatial analysis in geographical information systems. On Word Press, Santa Fe, USA.

4. Dimitriu G (2007). Sisteme informatice geografice (GIS). Editura Albastră, Cluj-Napoca. 